\title{
CUIDANDO DEMONIOS, VAMPIROS, HOMBRES LOBOS Y ZOMBIS A LO LARGO DE LA HISTORIA ENTRE LA REALIDAD Y LA FANTASIA
}

\section{CARING DEMONS, VAMPIRES, WEREWOLVES AND ZOMBIES IN HISTORY BETWEEN REALITY AND FANTASY}

\author{
Andrés Camargo-Sánchez
}

${ }^{1}$ RN.MSN. Estudiante Doctorado en Ciencias de la Salud, Profesor Programa de Enfermería, Facultad de Ciencias de la Salud. Universidad de Ciencias Aplicadas y Ambientales U.D.C.A, calle 222 No. 55-37, e-mail: andcamargo@udca.edu.co

Rev. U.D.C.A Act. \& Div. Cient. 19(2): 285-295, Julio-Diciembre, 2016

\section{RESUMEN}

Las enfermedades son tan antiguas como el hombre y cada enfermedad presenta una variedad propia de signos y de síntomas, que se ven reflejados en lo físico y en lo mental. Tienen, además, unas repercusiones sociológicas, dependiendo de sus manifestaciones clínicas, el estado del conocimiento actual, la ciencia y la religión, que las tratan de explicar. El objetivo a lo largo de este artículo es contrastar y reflexionar acerca de las explicaciones místicas y científicas de varias enfermedades, que atormentaron a quienes las padecían y a las sociedades, por el desconocimiento que existía hacia ellas y las consecuencias que trajo para quien las padecía. A partir de conceptos definidos por el autor, asociando mitos y enfermedades, se realizó una búsqueda sistemática y temática de literatura científica, donde como resultado, se encontró que esta asociación generó una época de irracionalismo y superstición a lo largo de la historia del hombre, desde la antigüedad hasta la actualidad. Se analizó la depresión y la ansiedad, la epilepsia, la parálisis del sueño, la porfiria, la hipertricosis, la licantropía clínica y la rabia, donde se encontró que estas enfermedades, por su cuadro clínico, dieron lugar a explicaciones erradas y místicas, que llevaron a la sociedad a aislar, rechazar y actuar, de manera violenta, hacia las personas que las sufrían, fomentando mitos, cuentos y leyendas, que fueron reforzados y trasmitidos de generación en generación, en el folclor por la tradición oral, la literatura, el arte y, actualmente, por el cine, la televisión y la Internet.

Palabras clave: Enfermedades, historia, magia, creencias, ciencias de la salud.

\section{SUMMARY}

Diseases are as old as human beings, every disease has a variety of signs and symptoms that are reflected in the physical and mental state, they also have sociological implications depending on their clinical manifestations and the explanations that science and religion gave to why these individuals were affected. The purpose throughout this paper it will be contrasted and reflected the mystical and scientific explanations of different diseases that have plagued humanity through history and the ignorance society have towards them. Concepts were stated by the authors based in mystical and medical explanations, guided methodology an exhaustive literature review using databases, this association generated an era of irrationality and superstition from ancient times to present times. Depression, anxiety, epilepsy, sleep paralysis, porphyria, hypertrichosis, clinical lycanthropy and rabies will be analyzed. Base on their clinical picture, which resulted in erroneous and mystical explanations that led society to isolate, reject and act violently towards patients suffering from these diseases. At the same time society created myths, tales and legends that were reinforced and transmitted from generation to generation by oral tradition, folklore, literature, art and now by films, television and internet.

Key words: Disease, History, Magic, Belief, Health Sciences.

\section{INTRODUCCIÓN}

A lo largo de la historia, el ser humano siempre se ha visto amenazado por dolencias que generan miedo e incertidumbre y en su afán de buscarle explicaciones lo ha llevado por caminos de herradura o caminos sin salida, donde, generalmente, las únicas explicaciones que encuentran son de tipo metafísico, mágico, fantástico y divino, las cuales, emergen frente a las manifestaciones clínicas y que se atribuyen al demiurgo creador, a espíritus o fuerzas sobrenaturales, que son más poderosos que la ignorancia humana. Las enfermedades no son ajenas a estas explicaciones y libros, como la Biblia, el Corán, el Talmud y los libros chinos e hindúes, que 
dan explicaciones y curas para las mismas (López-Moreno et al. 2000). De acuerdo con Pavía-Ruz et al. (1998), algunas veces, en culturas ancestrales, existía un grupo selecto de personas que, a través de su capacidad de sugestión, iniciaron las primeras prácticas curativas, mediante el uso de conjuros, empleo de pócimas y otros artificios, retando a esa ignorancia y buscando hacer frente a la patología.

Muchas patologías somáticas y psiquiátricas, que ahora se comprenden mejor, también sucumbieron a estas explicaciones y tratamientos, que por la complejidad de los signos, los síntomas y las manifestaciones clínicas, así como los comportamientos de quien las padece, han hecho que se creen de manera rápida y repetida, actitudes de estigmas y de rechazo a quien las sufre, hasta la actualidad (Maier et al. 2015; Seeman et al. 2015). Se mitifican y se les dan visos malévolos, demoniacos y oscuros, que son reforzados por la literatura, la religión, la música, la pintura y el cine, y se refuerzan estereotipos e imaginarios acerca de alguna patología, a través de la historia.

El objetivo de este artículo es describir algunas de las patologías que han atormentado, de manera singular, la existencia humana, en alguna época específica de la historia, lo que ha ocasionado miedo y terror, por el desconocimiento del curso natural de la enfermedad, la falta de tratamiento y lo deletéreo de sus signos, sus síntomas, por su asociación al mal, a demonios y monstruos.

\section{MATERIALES Y MÉTODOS}

A partir de conceptos definidos, se realizó una búsqueda sistemática, con el fin de extraer datos relevantes (Lefebvre et al. 2013) y temática de literatura científica publicada, relacionada con mitos, magia, demonios, vampiros, hombres lobos y zombies, enfermedades, depresión y ansiedad, epilepsia, parálisis del sueño, porfiria, hipertricosis, licantropía clínica y rabia, en bases de datos, como Pubmed, Medline, Scielo y Google Académico. El análisis, se realizó por parte del autor, experto en el tema de ciencia y arte aplicado al área de la salud. Para abstraer información relevante para este artículo, se tomó en cuenta una clasificación preliminar de artículos y se buscaron enlaces entre conceptos de mitos y de enfermedades, lo que permitió encontrar las explicaciones religiosas, místicas, mágicas y sobrenaturales, para luego contrastarlas con las descripciones de las entidades clínicas, a las que correspondían.

\section{RESULTADOS Y DISCUSIÓN}

Demonios y santos. Desde la época de Jesucristo, como se puede leer en la biblia, específicamente en el libro de Marcos, él expulsaba espíritus malignos, que habitaban en los hombres, que venían desde las tumbas, con cadenas en las manos y hierros en los pies; vagaban por colinas y cuevas de día y de noche, siempre gritando y cortándose con piedras y a quienes después de la mediación de Jesucristo, los vieron sentados, vestidos y en sano juicio, se asombraron ante los eventos y se preguntaban cंqué era en realidad estos fenómenos?

Ansiedad y depresión. Actualmente, se entiende que los trastornos mentales eran atribuidos a espíritus, posesiones demoniacas y pecados. Aunque es poca la información científica, la creencia en demonios -como la causa de enfermedades mentales-, es un fenómeno bien conocido. En muchas culturas del mundo, aún se cree en la posible causalidad de algunas de estas patologías, como resultado de la influencia de espíritus malignos, siendo etiquetado como posesiones demoniacas; por ejemplo, pacientes que padecen trastornos de ansiedad y esquizofrenia son tratados en rituales de exorcismo (Pfeifer, 1994; Mohr \& Huguelet, 2004).

Epilepsia. Otra entidad clínica muy común y conocida desde épocas inmemorables que se asociaba a posesiones demoniacas y fuerzas sobrenaturales fue la epilepsia, una interpretación apoyada por la historia del milagro de la curación del niño que convulsionaba, que se registra en tres evangelios de la biblia; sin embargo, se han dado muchas otras interpretaciones. La epilepsia, como consecuencia de hacer el mal o de las influencias lunares o mágicas y que se maneja con tratamientos basados en magia o religión, son situaciones que persisten en la modernidad (Gross, 1992; Eadie, 1993). En 1487, dos monjes dominicos publicaron un libro sobre brujas, titulado Malleus Maleficarum, en donde se decía que se habían identificado a las brujas, porque presentaban crisis convulsivas, como consecuencia de la epilepsia, como enfermedad de base. Esta afirmación, se cree costó la vida de entre cien mil y un millón de mujeres, quienes fueron quemadas en la hoguera (Nakken \& Brodtkorb, 2011); otras medidas comunes era someter al paciente a exorcismos, donde eran heridos y algunos de ellos murieron (Figura 1) (Franco-Rubio, 2009). Con el avance científico en el diagnóstico y el tratamiento, se tiene una mejor comprensión sobre la epilepsia, lo cual, ha mejorado considerablemente sus consecuencias sociales en el último siglo, aunque este conocimiento no está lo suficientemente popularizado en la población en general (Owczarek \& Jędrzejczak, 2013).

Es importante considerar que entre los signos de la epilepsia, principalmente la que se origina en el lóbulo temporal, se encuentran las experiencias religiosas, durante los estados convulsivos: sensación de perfecta armonía, presencia de Dios y un estado de éxtasis y delirios, que pueden durar varios días (Devinsky \& Lai, 2008; Brodtkorb \& Nakken, 2015). En la actualidad, existe cierta evidencia científica que un número de personas religiosas, incluyendo profetas, santos y fundadores de iglesias, pudieron haber tenido convulsiones origi- 


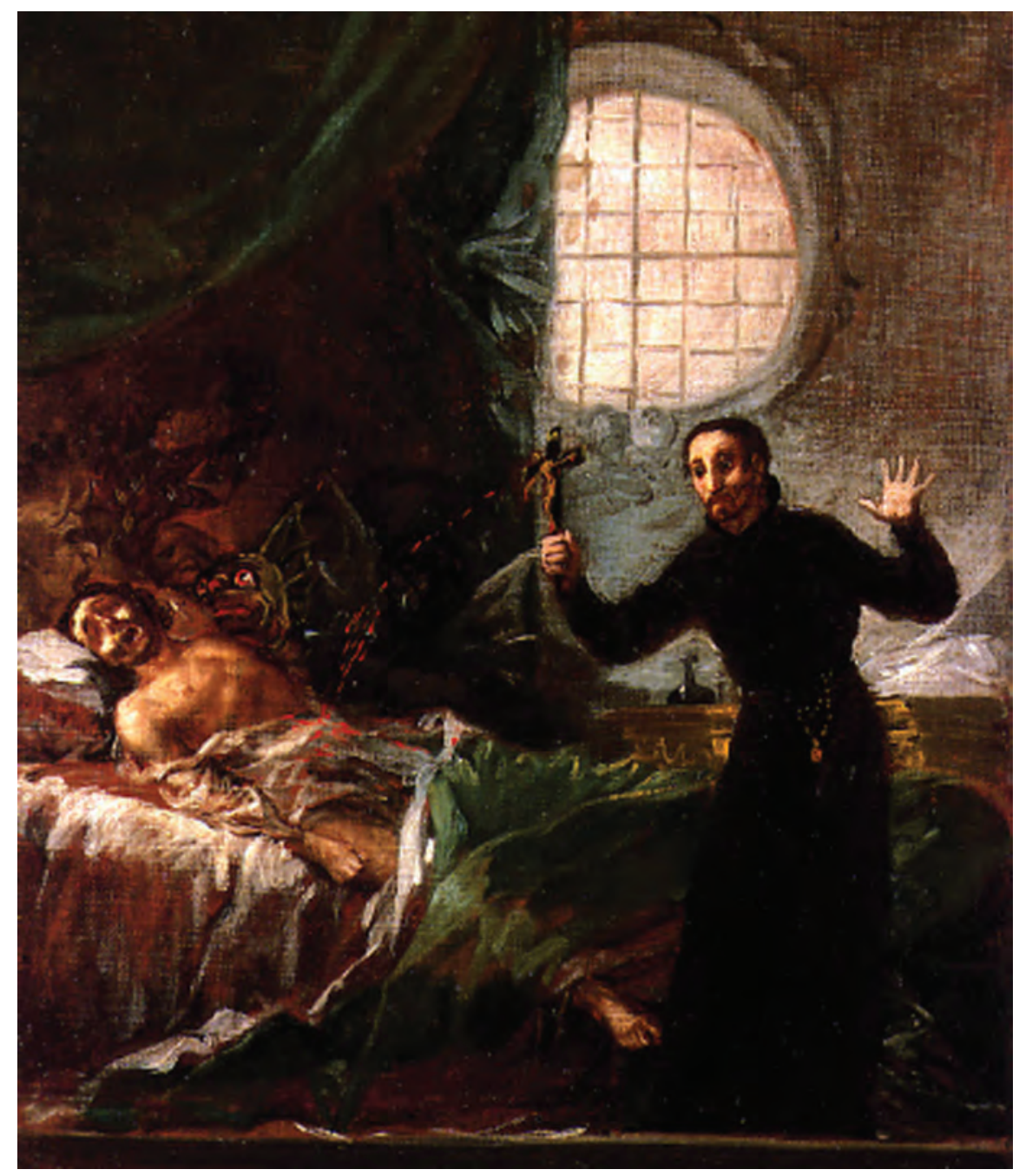

Figura 1. "San Francisco de Borja y el moribundo impenitente". Goya, 1788.

nadas por alteraciones del lóbulo temporal, probablemente, con grandes repercusiones en la religión y la literatura, como se conocen en la actualidad (Nakken \& Brodtkorb, 2011).

Parálisis del sueño. Hoy por hoy, ha cobrado importancia la frecuencia, la connotación cultural y su asociación a espíritus, los fenómenos paranormales que experimentan las personas, al quedarse dormidas o al despertar, con manifestaciones, como inmovilidad de brazos, piernas, cabeza, no poder hablar y, muchas veces, la percepción de una sombra humana. Experimentan una opresión en el pecho y dificultad para respirar, esta situación puede durar algunos segundos o varios minutos y tiene características aterradoras al sentir, ver y escuchar presencias demoniacas, que los tocan y hacen que leviten en sus cuartos (GIrard \& Cheyne, 2004; Hinton et al. 2005).
Esta situación es una entidad clínica bastante común y benigna, denominada -clínicamente- parálisis del sueño, que consiste en que la persona experimenta una parálisis mientras que el sistema sensorial está activo en la fase que se pasa del sueño a la vigilia, situación que es acompañada de alucinaciones (Jalal \& Ramachandran, 2014); su fisiopatología está relacionada con la hipotonía normal, que se percibe durante el sueño y, aparentemente, por un cambio disfuncional existente en el mecanismo que controla la parálisis motora normal del estado de sueño de movimientos oculares rápidos (REM) (Núñez, 2012) y esta situación clínica, se asocia a estrés, deprivación y hábitos irregulares de sueño o la posición al dormir (Huamaní et al. 2006). Se estima que entre el 40 y $50 \%$ de las personas lo han experimentado al menos una vez en su vida y, de acuerdo a la cultura, se ha asociado a espíritus, demonios, brujas y, recientemente, a abducciones extraterrestres (McNally \& Clancy, 2005; PerezPerez et al. 2010). 
Este fenómeno ha inquietado a la humanidad y se refleja en la pintura. La Pesadilla (Figura 2) (Harris, 2004), en la que un espíritu de la mitología nórdica atormentaba y sofocaba a mujeres traviesas, generando una morbosa opresión en el pecho durante la noche, se asoció a castigos divinos, por malos comportamientos en la vigilia (Vargas \& Camargo Sánchez, 2011). Siendo esta obra de arte una ilustración de un tema que tiene interés para las ciencias de la salud porque es de común incidencia, mucho tiempo después de que fuera plasmada en esta pintura se describió, por la medicina, dando claridad de su causa, signos, síntomas y tratamientos (Schneck, 1969).

Vampiros. Seres que particularmente aterrorizaron la Europa medieval por su poder y maldad, que se caracterizaban por una fuerza sobrehumana, inmortalidad, consumo de carne, sangre humana, fobia a la luz, así como la capacidad de convertirse en murciélago o, en neblina, durante las noches. Entre las medidas para combatir estos seres, se encontraba usar un collar de ajos, puesto que a estos seres los ahuyentaba su olor (Olivares-Merino, 2006; González-Treviño \& García Guerrero, 2008; Nad, 2016); sin embargo, hubo un vampiro en particular que llamó la atención por su extrema crueldad, conocido como Vlad el Empalador o Drácula, quien en realidad era Vlad Tepes Dracul, príncipe de Rumania (1431-1476), quien se caracterizaba por usar el empala- miento como método de tortura a sus enemigos y beber su sangre (Arriagada et al. 2009). Los vampiros han atormentado por siglos a la humanidad y han causado curiosidad, llevándolos a ser inmortalizados en la literatura, con la novela del escritor irlandés Bram Stoker, en 1897, que luego fue llevada al cine, por el director Francis Ford Coppola y protagonizada por Gary Olman ganando varios premios Óscar, entre ellos a mejor maquillaje, por recrear las características físicas de estos seres.

Al igual que en el libro, se describe su fisionomía: su cara era muy fuerte, aguileña, con un puente muy marcado sobre la fina nariz y sus ventanas peculiarmente arqueadas; con una frente alta y despejada y el pelo gris que le crecía escasamente alrededor de las sienes, pero profusamente en otras partes; sus cejas eran muy espesas, casi se encontraban en el entrecejo, y con un pelo tan abundante que parecía encresparse por su misma profusión; la boca, por lo que podía ver de ella bajo el tupido bigote, era fina y tenía una apariencia más bien cruel, con unos dientes blancos característicamente agudos, que sobresalían sobre los labios, cuya notable rudeza mostraba una singular vitalidad, en un hombre de su edad. En cuanto a lo demás, sus orejas eran pálidas y extremadamente puntiagudas en la parte superior; el mentón era amplio y fuerte, y las mejillas firmes, aunque delgadas y la tez era de una palidez extraordinaria (Stoker, 2014). Como

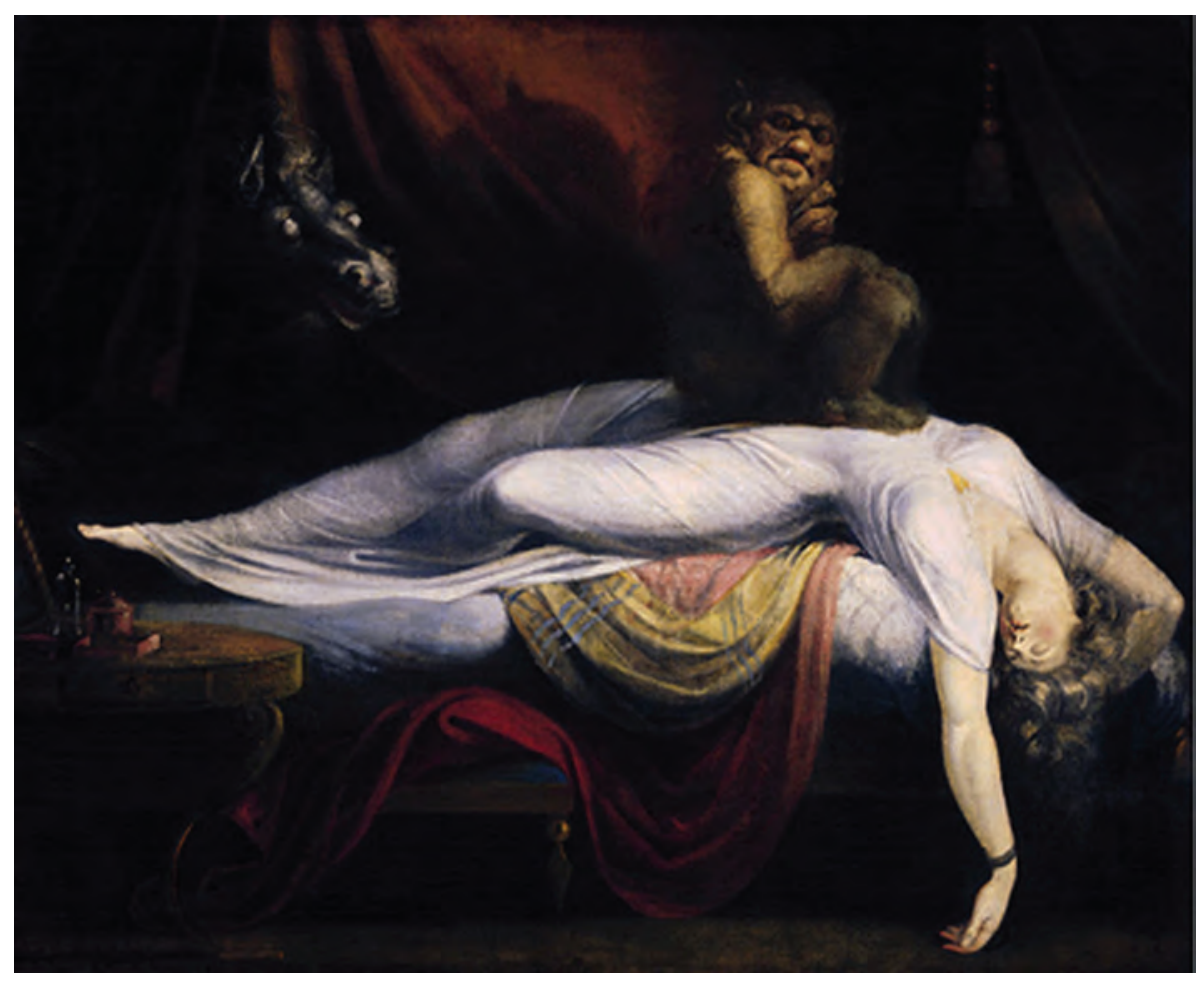

Figura 2. "La pesadilla”. Henry Fuseli, 1781. 
se observa en este relato y en la película, se pueden percibir una serie de signos y síntomas que más que un monstruo muestran a una persona enferma.

Porfiria. A pesar que Vlad Tepes Dracul murió en batalla, su fisonomía permite sospechar que pudo haber padecido una rara enfermedad hematológica, denominada porfiria, que es un trastorno metabólico causado por deficiencias en la actividad de las enzimas que participan en la biosíntesis del grupo hemo. Estas alteraciones enzimáticas conducen a la sobreproducción y la acumulación de los metabolitos intermedios, porfirinas y precursores, que son sustrato de las enzimas deficitarias (Rossetti et al. 2007), que explicaría algunas características vampirescas, como hipertricosis y encías retraídas, cuyo aspecto aparenta la existencia de colmillos, junto a una rara coloración de los dientes, conocida como eritrodoncia y otras alteraciones dentarias (Figura 3).

Además, se acompaña de anemia con rubicundez labial y palidez facial subsecuentes; fotosensibilidad en la piel y las mucosas, que provoca fotofobia, situación que, junto con el sonambulismo, obligaría a desarrollar hábitos nocturnos (González-Treviño \& García Guerrero, 2008); también, por ser una enfermedad con un componente genético autosómico recesivo, que era potenciada por matrimonios incestuosos, situación común en la nobleza europea de la época. Una explicación razonable a su crueldad y maldad puede radicar en el rechazo social y malos tratos a los que eran sometidos, junto a un componente siquiátrico, que podía desarrollar (Lorenzo et al. 2014). Pero ćpor qué el ajo ahuyentaba a los vampiros? La respuesta radica en la capacidad de ciertos compuestos de esta planta, para inducir unas enzimas que agravan aún más la anemia y el daño grave de la piel cuando hay exposición a la luz solar (Maas \& Voets, 2014).

Es irónico, que el folclor alimentara la idea que, para la supervivencia de los vampiros, se aprovechara de las personas bebiendo su sangre, cuando, en la actualidad, uno de los tratamientos más usados para el control de la porfiria es la flebotomía constante (Mlacker et al. 2015).

Hombres lobo. También conocido como licántropo, del griego lukos, que significa lobo y anthropos, hombre, una criatura legendaria presente en muchas culturas independientes a lo largo del mundo, siendo tan común y universal en el folclor, la literatura y el cine, como los vampiros. Otro concepto importante que aparece en los relatos es la capacidad de convertirse en hombre lobo, con pelo en todo el cuerpo bajo la influencia de la luna llena. Trasformación que resultaba dolorosa y donde actuaban más por instinto, ganando el temperamento animal, enajenando la razón de sus actos y buscando saciar su apetito, basado en el consumo de carne humana y pequeños animales (de Sousa, 2013).

Hipertricosis. Es un grupo de patologías relativamente raras y que son conocidas desde hace siglos. Consiste en un aumento excesivo de lanugo, pelo velloso o terminal que aparece de manera independiente de la edad, raza o sexo y que afecta zonas del cuerpo, no dependientes de estímulos androgénicos. Muchos de los que la padecían eran asociados

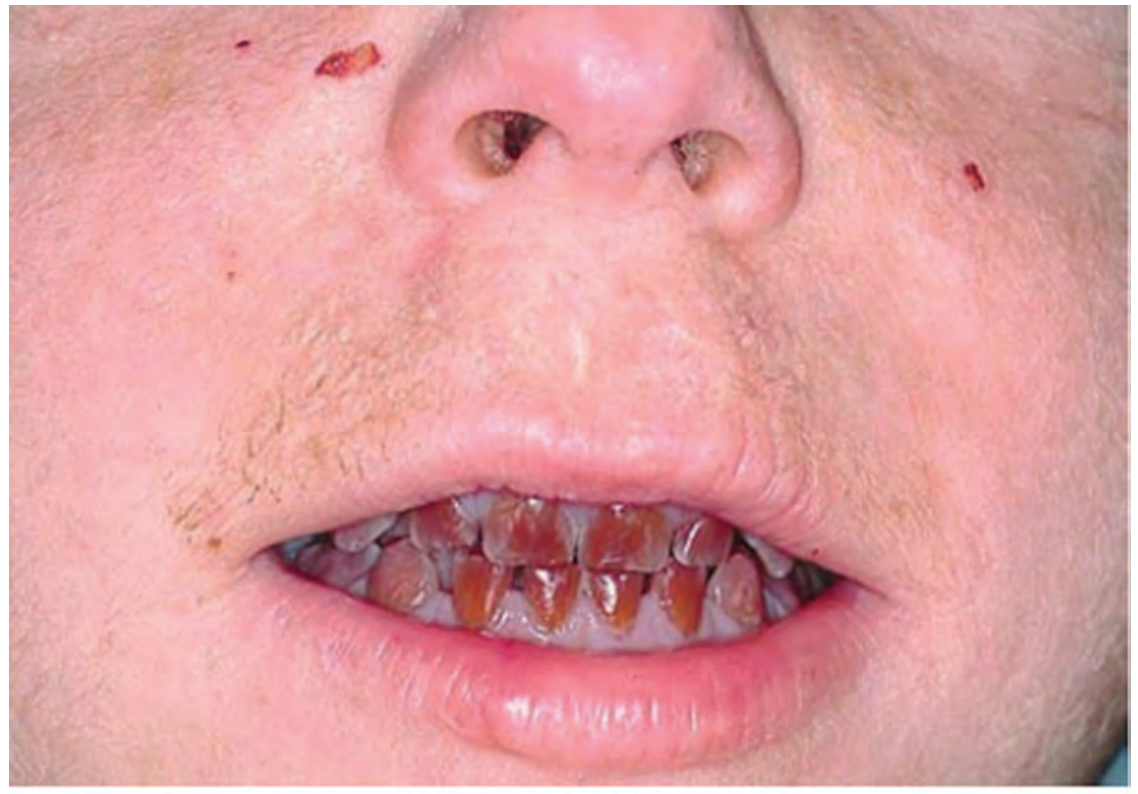

Figura 3. Aspecto de colmillos en un paciente con porfiria, generados por los cambios en la coloración de los dientes y en la estructura de las encías. 
a hombres lobos (Figura 4) o expuestos en circos, siendo el más conocido el ruso Theodoro Petrov, apodado Jo Jo, el niño cara de perro o Sky Terrier; además, han sido representados en el arte y en la escultura de la edad media y el renacimiento (Sigall et al. 2011).

Entre las causas más comunes, se encuentran las genéticas, congénitas, neoplasias benignas o malignas y efectos secundarios a algunos medicamentos o la anorexia nerviosa (Katritzky, 2014; Pavone et al. 2015; Rampon et al. 2016); dentro de las complicaciones de esta patología, se deben tener en cuenta las implicaciones estéticas y cosméticas. Es necesario realizar una buena historia clínica, para suministrar un tratamiento adecuado al paciente, incluyendo, la eliminación del vello con láser (Trüeb, 2008), con el propósito de disminuir la estigmatización, que hacían que estos pacientes salieran en la noche como lobos (Bénézech \& Chapenoire, 2005), aunque las medidas de rechazo, en esta época, no son tan violentas como en la antigüedad. a.

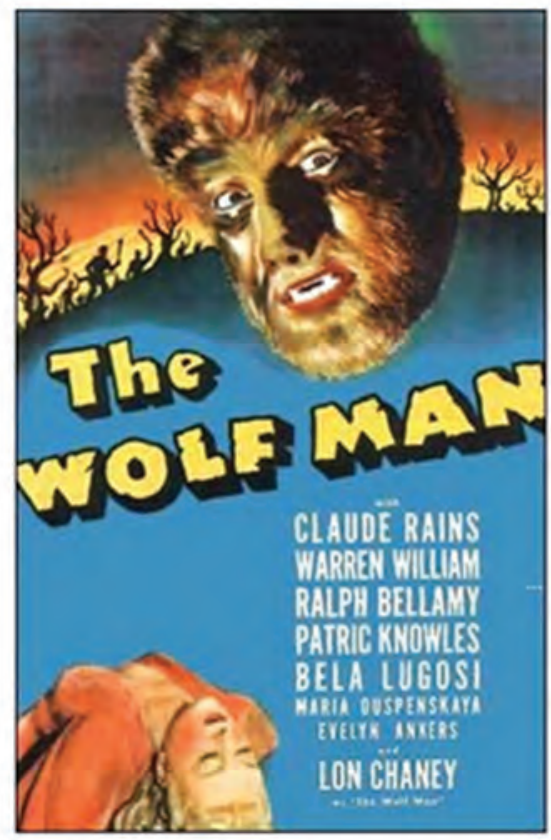

b.

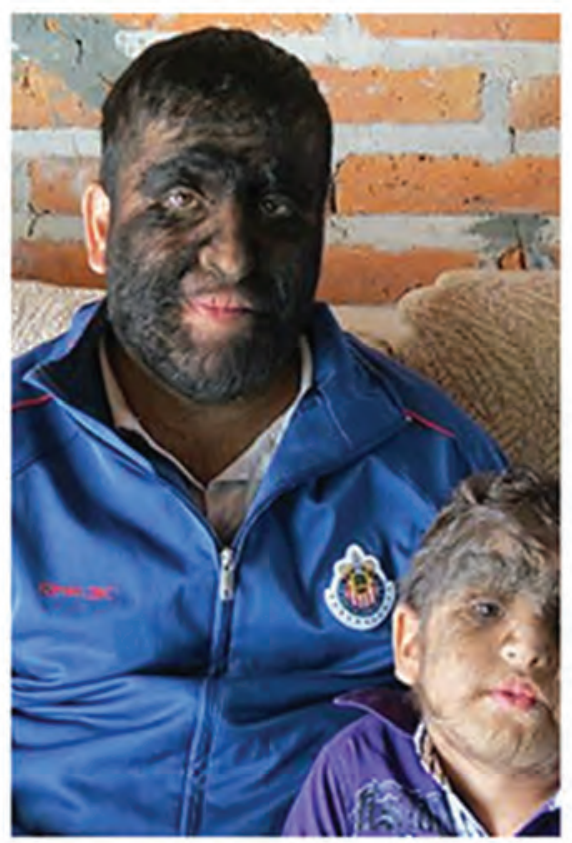

Figura 4. Similitudes entre la descripción del hombre lobo y la hipertricosis a) Película "El hombre lobo" (1941) (Waggner, 2016); b) Caso de hipertricosis congénita lanuginosa (BBC Mundo, 2016).

Licantropía clínica. Es una entidad siquiátrica, descrita por primera vez en el siglo XVII, como una forma de locura; sin embargo, en los siglos XIX y XX, los reportes de casos son extremadamente raros (Fahy, 1989). La licantropía es una creencia inusual o ilusión que la persona que la padece se ha transformado en un animal y adquieren comportamientos o sentimientos acordes a tal creencia. Generalmente, los delirios licantrópicos se asocian a trastornos depresivos mayores, con síntomas psicóticos; estos delirios son agudos y rápidamente reversibles y están influenciados por el entorno cultural del paciente (Khalil et al. 2012); sin embargo, ninguna de las entidades clínicas, anteriormente descritas, aclara la influencia de la luna en los llamados hombre lobo.
Una posible hipótesis de este fenómeno, se presenta desde la fisiología y el comportamiento humano y de los animales, que están sujetos a ciclos estacionales, lunares y circadianos. Los ritmos circadianos y estacionales han sido bastante estudiados; no obstante, se sabe poco acerca de los efectos del ciclo lunar en animales (Molaee Govarchin Ghalae et al. 2011) y la evidencia de estas asociación en el ser humano, es débil. Recientemente, se reportó una duración menor del sueño en luna llena en dos pequeñas muestras de adultos y se ha asociado con una mayor prevalencia de problemas de sueño, de convulsiones, de eventos cardiovasculares, de comportamientos antisociales y de problemas mentales (Foster \& Roenneberg, 2008; Molaee Govarchin Ghalae, 2011; Sjödin et al. 2015). 
Aunque no está claro el efecto de la luna en la fisiología humana y con la creencia que así era, se podría explicar sobre el principio que el cuerpo humano contiene $80 \%$ de agua y que la luna ejerce su influencia, como las mareas, debido a su gravedad. Se destacan dos puntos en esta hipótesis: primero, las fuerzas gravitacionales que generan las mareas dependen de la distancia entre la tierra y la luna, no en la alineación de la luna, la tierra y el sol; lo que genera las fases lunares, donde la luna llena no significa un efecto gravitatorio específico en la tierra y segundo, la gravedad es una fuerza muy débil, se sabe que la luna influye en las mareas oceánicas y que no produce las mareas en los cuerpos de agua más pequeñas, tales como lagos e, incluso, algunos mares y, mucho menos, en un ser humano (Foster \& Roenneberg, 2008).

Zombis. Las personas que vuelven de la muerte, los llamados muertos vivientes y que en la actualidad ocupan un lugar especial en la nuestra cultura occidental, por las series de televisión que abordan este tema y que son de gran audiencia mundial, con una fascinación mórbida, que se ha extendido a lo largo de los siglos.

El origen de zombis, se remonta al folclor de varias tribus en África occidental, quienes durante el comercio de esclavos, de finales del siglo XVI y hasta el XVIII, migraron a América, para cultivar plantaciones en el caribe y servir en las colonias europeas, que traían con ellos la cultura de la magia del vudú y los hechizos, que se conserva hasta hoy, principalmente, en el oeste de África, Haití, Nueva Orleans y algunos lugares de las islas del caribe, estrechamente relacionado con la esclavitud y la represión (Nasiruddin et al. 2013). Se puede asociar a personas sin alma, que se dedicaban a trabajos forzados.

En el folclor haitiano, se cree que los brujos tienen el poder de dividir el cuerpo del alma o de traer nuevamente a la vida a quien ha fallecido, por medio de rituales, pócimas y rezos especiales, generando un ente que controlan a voluntad; no obstante, se describe al zombi como un ser en estado de estupor, sin brillo en la mirada, con un andar torpe, con vocalizaciones y movimientos repetitivos simples (Littlewood \& Douyon, 1997) y con sus tejidos en descomposición.

Esta descripción ha sido ampliamente difundida al presente, a través del famoso video clip Thriller, de Michael Jackson, en 1985, en la película de terror La noche de los muertos vivientes, del director Tom Savini, en 1990, la serie de televisión The Walking Dead, estrenada en el 2000, que describe un mundo post apocalíptico, en el que un grupo de humanos tratan de sobrevivir a los zombis salvajes; sin embargo, hay una película protagonizada por Brat Pitt y estrenada en el 2013, llamada Guerra mundial Z, donde surge una epidemia en todo el mundo, de rápida propagación, de un agente patógeno que convierte a las personas en zombis y se conta- gian por la mordedura de uno infectado. Esta película muestra, principalmente, el miedo que, hoy por hoy, se tiene no solo a los zombis, sino a agentes biológicos infecciosos de gran patogenicidad y de fácil contagio, que en cuestión de horas puede infectar varios lugares del mundo. Los alcances de la medicina, en cuanto a prevención de enfermedades, aún están insipientes, como ha ocurrido con ciertos agentes biológicos, como el ántrax, el H1N1, el ébola y, actualmente, el zika, que atemorizan al mundo contemporáneo, como en su tiempo lo hicieron muchos de los personajes que hasta ahora se han descrito, llevando este tema a la especulación, elucubración y el miedo acerca de la mutación de cepas de agentes infecciosos, que puedan acabar con la especie humana. Para poner en contexto esta situación y facilitar la explicación de contagio, manifestaciones clínicas y tratamiento, se va describir la enfermedad de la rabia, que comparte similitudes con la descripción de los llamados zombis en la actualidad (Tabla 1) (Nasiruddin et al. 2013).

La rabia. Es una patología descrita desde hace más de 4.000 años, tal vez por su cuadro clínico tan impresionante y bizarro; esta patología ha sido ampliamente descrita por grandes historiadores y médicos de la antigüedad (Schneider \& Santos-Burgoa, 1994; Toro \& Raad, 1997). Es una patología zoonótica infecto-contagiosa de origen viral, caracterizada por una infección aguda del sistema nervioso central. El medio de contagio más común es por la mordedura de un animal contagiado, primera similitud con los zombis y el periodo de incubación, en promedio, es de tres semanas. Dentro de los signos y los síntomas, se puede encontrar ansiedad, obnubilación, desorientación, agitación, dificultad para la deglución, taquicardia, reflejos exagerados o disminuidos, insomnio, alucinaciones, delirio y convulsiones $\mathrm{y}$, algunas veces, sialorrea, trismus, cefalea y, con menor frecuenta, alguna tendencia a morder (Toro \& Raad, 1997), como una segunda similitud con los zombis.

En 2008, en Bali, Indonesia, se sacrificaron aproximadamente 50.000 perros en cinco días, después de un brote de rabia, lo que ocasionó grandes críticas y controversias. Resultado de ello, se llevó a cabo la vacunación masiva; es la tercera y cuarta similitud con un posible apocalipsis zombi. La rápida propagación y la eliminación -como medio de control-, donde los humanos supervivientes que no tengan la capacidad de vacunación masiva es sacrificar a los zombis, como la única opción, para garantizar su supervivencia (Nasiruddin et al. 2013). El tratamiento es paliativo y sintomático, con lo que se busca evitar el sufrimiento innecesario al paciente y la vacunación. Hasta ahora no se han reportado casos de contagio entre personas.

Cada época tiene su locura particular y la sociedad y las ciencias de la salud, no son ajenas a esto. A través de este artículo, se realizó una descripción histórica para dilucidar, desde 
Tabla 1. Comparación de zombis, según lo reportado en el folclor y la epidemiología de la rabia (Nasiruddin et al. 2013).

\begin{tabular}{|l|c|c|}
\hline Característica & Zombis & Rabia \\
\hline Susceptibilidad & $\begin{array}{c}\text { La infección humana requiere un ambiente } \\
\text { de ficción apocalíptica }\end{array}$ & $\begin{array}{c}\text { Requiere ambiente con animales infectados, como } \\
\text { perros o murciélagos }\end{array}$ \\
\hline Causa & $\begin{array}{c}\text { Virus-T (virus ficticios), otros virus, } \\
\text { patógenos desconocidos }\end{array}$ & Mononegavirales \\
\hline $\begin{array}{l}\text { Medio de tras- } \\
\text { misión }\end{array}$ & $\begin{array}{c}\text { Mordeduras y rasguños; patógenos } \\
\text { desconocidos; contagio humano- hu- } \\
\text { mano; 100\% de efectividad }\end{array}$ & $\begin{array}{c}\text { Mordeduras; saliva infectada con el virus de la rabia; } \\
\text { contagio animales a humanos }\end{array}$ \\
\hline Virulencia & $\begin{array}{c}\text { Las víctimas mueren y se convierten en } \\
\text { muertos vivientes }\end{array}$ & $\begin{array}{c}\text { Las víctimas mueren y quedan muertos } \\
\text { Síntomas }\end{array}$ \\
$\begin{array}{c}\text { Fiebre, escalofríos, pérdida de cabello y } \\
\text { pigmentación, alteraciones de la marcha }\end{array}$ & $\begin{array}{c}\text { Delirio, ansiedad, estrés, alucinaciones, espasmos } \\
\text { musculares, convulsiones }\end{array}$ \\
\hline $\begin{array}{l}\text { Métodos de } \\
\text { control }\end{array}$ & $\begin{array}{c}\text { Evitar la mordida de los zombis existentes } \\
\text { y destruir la cabeza de los zombis }\end{array}$ & $\begin{array}{c}\text { Evitar mordeduras de perros y los murciélagos; } \\
\text { profilaxis post-exposición }\end{array}$ \\
\hline
\end{tabular}

un punto de vista científico, diferentes patologías que han atormentado a la humanidad, desde la antigüedad hasta la actualidad, que se combinan entre la fantasía y la realidad, causando miedo, caos, terror, violencia y, ante todo, un desconocimiento de sus causas, explicándolas, generalmente, de manera errada, lo que ha conducido a un aislamiento y rechazo de quien las padece.

Vale la pena la pregunta: ¿Quiénes son en realidad los verdaderos monstruos?, cंquiénes la padecen o la sociedad que los excluye, los juzga y actúa algunas veces de manera violenta hacia quien las padece? Es deber de los profesionales y científicos de la salud explicar, desmitificar y humanizar aquellas patologías, junto con sus causas, trasmisión, signos y síntomas, que causan deformaciones, mutilaciones, comportamientos no aceptados socialmente, puesto que estas personas requieren cuidados y curación especial. Generalmente, las repercusiones de una patología son psicológicas y fisiológicas y el paciente necesita explicaciones para asumir su proceso de enfermedad.

Las enfermedades también tienen repercusiones sociológicas: la afección de los pacientes influye en la conducta de las sociedades en que viven, pero su rechazo o aceptación también modula la vivencia personal de la enfermedad (Baños, 2003); en nuestros días, al igual que en la antigüedad, se juzgan y se discriminan las personas enfermas y un ejemplo claro es quienes padecen VIH-Sida, que aún tienen un estigma social y se tratan a veces como monstruos, donde se ven aun las enfermedades como castigo divino (Camargo Sánchez \& Gutiérrez-Díaz, 2011). Lo mismo sucede con los trastornos psiquiátricos.

\section{CONCLUSIONES}

Implicaciones para la práctica y la docencia en ciencias de la salud. Conocer la historia de las enfermedades no solo desde un punto de vista fisiopatológico, sino desde lo cultural y sociológico, permite agudizar al médico y a la enfermera la denominada pericia clínica, que consiste en el proceso de actuación de los profesionales de la salud relacionada con la atención del paciente. Sus componentes son la información clínica obtenida, las percepciones, los razonamientos, los juicios, los procedimientos utilizados, las decisiones y las intervenciones que se aplican.

Esta pericia clínica debe iniciar con el término "ojo clínico", que consiste en la capacidad que poseen algunos profesionales de la salud para realizar diagnósticos rápidos y certeros (Gudiol Munté, 2006), basados, generalmente, en los signos, en lo que se puede observar al examen físico, en los síntomas y en lo subjetivo que refiere el paciente; sin embargo, para agudizar esta capacidad de diagnóstico no solo es necesario el conocimiento en las ciencias biológicas y las ciencias biomédicas, también se hace indispensable conocer cómo los signos y los síntomas de muchas enfermedades han sido descritos popularmente, pasando por la literatura, la poesía, la pintura, la música, el cine y la televisión, lo que permite ver la situación desde el lado de la gente común y corriente, a través de la historia, donde las explicaciones intuitivas, místicas, mágicas y religiosas estaban al orden del día (Baños, 2003; Barbado-Hernández, 2007; Ciuffolini et al. 2007). 
Además, desde la experiencia del autor, conocer los signos y los síntomas de muchos procesos biológicos, por medio de la literatura, la música y el arte (Camargo Sánchez \& Vargas, 2011; Vargas \& Camargo Sánchez, 2011; Vargas Vargas \& Camargo Sánchez, 2013), permitirá ser mejores docentes, al contar con suficientes elementos pedagógicos, para los procesos de enseñanza; sobresalientes profesionales de la salud, al identificar, por medio del discurso del paciente, sus dolencias y afecciones y excelentes seres humanos, al valorar la historia y enriquecer el espíritu.

Conflicto de intereses: El manuscrito fue preparado y revisado por el autor, quien declara que no existe conflicto de intereses que ponga en riesgo la validez de los resultados presentados.

\section{BIBLIOGRAFÍA}

1. ARRIAGADA, R.; GÓMEZ, J.; SANTANA, R.; MARTEL, K.; MORALES, C. 2009. Empalamiento tóraco-abdominal: Reporte de un caso. Rev Chil. Cir. 61(4):366369.

2. BAÑOS, J.E. 2003. El valor de la literatura en la formación de los estudiantes de medicina. Educ. Méd. 6(2):37-43.

3. BARBADO HERNÁNDEZ, F.J. 2007. Medicina y literatura en la formación del médico residente de medicina interna. An. Med. Interna. 24(4):195-200.

4. BBC Mundo. 2016. La dura vida de la familia lobo de México - BBC Mundo. [online] disponible en: http:// www.bbc.com/mundo/noticias/2014/07/140711_ mexico_familia_lobo_msd (con acceso 25/01/2016).

5. BÉNÉZECH, M.; CHAPENOIRE, S. 2005. Lycanthropy: Wolf-men and Werewolves. Acta Psychiatr Scand. 111(1):79.

6. BRODTKORB, E.; NAKKEN, K.O. 2015. The relationship between epilepsy and religiosity illustrated by the story of the visionary mystic Wise-Knut. Epilepsy Behav. 46:99-102.

7. CAMARGO SANCHEZ, A.; VARGAS, A. 2011. Ritmos circadianos: una realidad compleja implícita en algunas obras literarias. Actual. Enferm. 14(2):42-47.

8. CAMARGO-SÁNCHEZ, A.; GUTIÉRREZ-DÍAZ, D.P. 2011. Cuidar es también aprender a escuchar. Arch Memoria. $8(1): 11-14$.
9. CIUFFOLINI, M.B.; DIDONI, M.; JURE, H.; PINERO, A. 2007. Cine y literatura como elementos para la mediación pedagógica: Una experiencia desde la medicina familiar. Arch. Medicina Familiar. 9(3):142-145.

10. de SOUSA, G.M. 2013. Licantropia nos percalços da História. Miguilim. 2(1):57-67.

11. DEVINSKY, O.; LAI, G. 2008. Spirituality and religion in epilepsy. Epilepsy Behav. 12(4):636-643.

12. EADIE, M.J. 1993. The understanding of epilepsy across three millennia. Clin. Exp. Neurol. 31:1-12.

13. FAHY, T.A. 1989. Lycanthropy: a review. J. R. Soc. Med. 82(1):37-39.

14. FOSTER, R.G.; ROENNEBERG, T. 2008. Human responses to the geophysical daily, annual and lunar cycles. Curr Biol. 18(17):R784-R794.

15. FRANCO-RUBIO, G.A. 2009. Introducción: historiar la vida cotidiana en la España moderna. Cuadernos de Historia Moderna. Anejos. (8):11-30.

16. GIRARD, T.A.; CHEYNE, J.A. 2004. Spatial characteristics of hallucinations associated with sleep paralysis. Cogn Neuropsychiatry. 9(4):281-300.

17. GONZÁLEZ-TREVIÑO, J.L.; GARCÍA GUERRERO, C.J. 2008. Vlad Tepes Dracul, Drácula y la fotofobia. Med Univer. 10(38):47-49.

18. GROSS, R.A. 1992. A brief history of epilepsy and its therapy in the Western Hemisphere. Epilepsy Res. 12(2):65-74.

19. GUDIOL MUNTÉ, F. 2006. "Ojo clínico” y evidencia científica. Rev. Fundación Educ. Médica. 9(Número Extraordinario 1):21-23.

20. HARRIS, J.C. 2004. The nightmare. Arch Gen Psychiatry. 61(5):439-440.

21. HINTON, D.E.; PICH, V.; CHHEAN, D.; POLLACK, M.H. 2005. The ghost pushes you down: sleep paralysistype panic attacks in a Khmer refugee population. Transcult. Psychiatry. 42(1):46-77.

22. HUAMANÍ, C.; MARTÍNEZ, A.; MARTÍNEZ, C.; REYES, A. 2006. Prevalencia y presentación de la parálisis del sueño en estudiantes de Medicina Humana de la UNMSM. An. Fac. med. 67(2):168-172. 
23. JALAL, B.; RAMACHANDRAN, V.S. 2014. Sleep paralysis and "the bedroom intruder": The role of the right superior parietal, phantom pain and body image projection. Med. Hypotheses. 83(6):755-757.

24. KATRITZKY, M.A. 2014. A wonderfull monster borne in Germany': hairy girls in medieval and early modern German book, court and performance culture. Ger. Life Lett. 67(4):467-480.

25. KHALIL, R.B.; DAHDAH, P.; RICHA, S.; KAHN, D.A. 2012. Lycanthropy as a culture-bound syndrome: a case report and review of the literature. J. Psychiatr. Pract. 18(1):51-54.

26. LEFEBVRE, C.; GLANVILLE, J.; WIELAND, L.S.; COLES, B.; WEIGHTMAN, A.L. 2013. Methodological developments in searching for studies for systematic reviews: past, present and future? Syst. Rev. 2:78. DOI: http://dx.doi.org/10.1186/2046-4053.

27. LITTLEWOOD, R.; DOUYON, C. 1997. Clinical findings in three cases of zombification. Lancet. 350(9084):1094-1096.

28. LÓPEZ-MORENO, S.; GARRIDO-LATORRE, F.; HERNÁNDEZ-AVILA, M. 2000. Desarrollo histórico de la epidemiología: su formación como disciplina científica. Salud Publ. Mex. 42(2):133-143.

29. LORENZO, C.B.; DE DIEGO, M.C.; ALDEHUELO, R.S.; ALONSO, C.V.; TAPIA, A.G. 2014. Porfirias y vampirismo. Más dermatología. 22:16-21.

30. MAAS, R.P.; VOETS, P.J. 2014. The vampire in medical perspective: myth or malady? QJM. 107(11):945946.

31. MAIER, T.; MOERGELI, H.; KOHLER, M.; CARRARO, G.E.; SCHNYDER, U. 2015. Mental health professionals' attitudes toward patients with PTSD and depression. Eur. J. Psychotraumatol. 6. doi:http:// dx.doi.org/10.3402/ejpt.v6.28693.

32. MCNALLY, R.J.; CLANCY, S.A. 2005. Sleep paralysis, sexual abuse, and space alien abduction. Transcult Psychiatry. 42(1):113-122.

33. MLACKER, S.; SHAH, V.V.; ALSAIDAN, M.; NOURI, K. 2015. Victorian vampires validated-the similarities between a legendary creature and a dermatologic pathology. JAMA Dermatol. 151(11):1225.
34. MOHR, S.; HUGUELET, P. 2004. The relationship between schizophrenia and religion and its implications for care. Swiss Med. Wkly. 134:369-376.

35. MOLAEE GOVARCHIN GHALAE, H.; ZARE, S.; CHOOPANLOO, M.; RAHIMIAN, R. 2011. The lunar cycle: effects of full moon on renal colic. Urol. J. 8(2):137.

36. NAD, J. 2016. Sava Savanović: el primer vampiro serbio y los muertos vivientes de los Balcanes. Balajú. 3:116-121.

37. NAKKEN, K.O.; BRODTKORB, E. 2011. Epilepsy and religion. Tidsskr Nor. Laegeforen. 131(13-14):12941297.

38. NASIRUDDIN, M.; HALABI, M.; DAO, A.; CHEN, K.; BROWN, B. 2013. Zombies--a pop culture resource for public health awareness. Emerg. Infect. Dis. 19(5):809-813.

39. NÚÑ̃̃EZ, J.E. 2012. Parálisis del Sueño. Synapsis. 3(2):14-18.

40. OLIVARES-MERINO, E.M. 2006. El vampiro en la Europa medieval: el caso inglés. Cuad. CEMYR. 14:205-232.

41. OWCZAREK, K.; JĘDRZEJCZAK, J. 2013. Christianity and epilepsy. Neurol. Neurochir. Pol. 47(3):271-277.

42. PAVÍA-RUZ, N.; CEBALLOS-QUINTAL, J.M.; MEDINAESCOBEDO, C.; ORDOÑEZ-DURÁN, A.; RÍOS-RODRÍGUEZ, H. 1998. Magia, religión y medicina. Rev. Biomed. 9:192-198.

43. PAVONE, P.; PRATICÒ, A.D.; FALSAPERLA, R.; RUGGIERI, M.; ZOLLINO, M.; CORSELLO, G.; NERI, G. 2015. Congenital generalized hypertrichosis: the skin as a clue to complex malformation syndromes. Ital. J. Pediatr. 41(1):1-8.

44. PEREZ-PEREZ, H.; PÉREZ-LORENSU, P.J.; DE JUANHERNÁNDEZ, P. 2010. Hypnopompic sleep paralysis with hallucinations and exploding head (corrected) syndrome: an infrequent association. Rev. Neurol. 51(4):255-256.

45. PFEIFER, S. 1994. Belief in demons and exorcism in psychiatric patients in Switzerland. Br. J. Med. Psychol. 67(3):247-258.

46. RAMPON, G.; HENKIN, C.; SOUZA, P.R.; ALMEIDA, H.L. Jr. 2016. Infantile generalized hypertrichosis caused 
by topical minoxidil. An. Bras. Dermatol. 91(1):8788.

47. ROSSETTI, M.V.; PARERA, V.E.; MELITO, V.A.; BATLLE, A. 2007. Porfiria congénita eritropoyética en la Argentina: 4 niños y un caso de manifestación tardía. Acta Bioquím. Clín. Latinoam. 41(3):359-367.

48. SCHNECK, J.M. 1969. Henry Fuseli, nightmare, and sleep paralysis. JAMA. 207(4):725-726.

49. SCHNEIDER, M.C.; SANTOS-BURGOA, C. 1994. Tratamiento contra la rabia humana: un poco de su historia. Rev. Saúde Pública. 28(6):454-63.

50. SEEMAN, N.; TANG, S.; BROWN, A.D. 2015. World survey of mental illness stigma. J. Affect. Disord. 190:115-121.

51. SIGALL, D.A.; SALAS-ALANÍS, J.C.; BEIRANA, A.; ARENAS, R. 2011. Hipertricosis: sus causas, formas clínicas y manejo. Dermatología CMQ. 9(1):35-44.

52. SJÖDIN, A.; HJORTH, M.F.; DAMSGAARD, C.T.; RITZ, C.; ASTRUP, A.; MICHAELSEN, K.F. 2015. Physical activity, sleep duration and metabolic health in children fluctuate with the lunar cycle: science behind the myth. Clin. Obes. 5(2):60-66.
53. STOKER, B. 2014. Drácula 1897. Bram Stoker. Versión en español. Disponible desde Internet en: https:// books.google.com.co/books?isbn $=9876345125$ (con acceso 25/01/2016).

54. TORO, G.; RAAD, J. 1997. Rabia. Biomédica. 17(1):1826.

55. TRÜEB, R.M. 2008. Hypertrichose. Hautarzt. 59(4):325338.

56. VARGAS VARGAS, R.A.; CAMARGO-SÁNCHEZ, A. 2013. Ritmos circadianos presentes en la danza de la vida: "de la concepción a la muerte". Actual. Enferm. 16(2):35-42.

57. VARGAS, R.; CAMARGO-SÁNCHEZ, A. 2011. El sueño un fenómeno biológico inspirador de arte. Actual Enferm. 14(4):34-39.

58. WAGGNER, G. 2016. El Hombre Lobo (1941). [online] FilmAffinity. Disponible desde Internet en: http:// www.filmaffinity.com/es/film965463.html (con acceso $25 / 01 / 2016$ ).

Recibido: Abril 8 de 2016

Aceptado: Octubre 6 de 2016

\section{Cómo citar:}

Camargo-Sánchez, A. 2016. Cuidando demonios, vampiros, hombres lobo y zombis a lo largo de la historia entre la realidad y la fantasía. Rev. U.D.C.A Act. \& Div. Cient. 19(2): 285-295. 